\title{
Two decades of RNA as I see it
}

\author{
YONGSHENG SHI \\ Department of Microbiology and Molecular Genetics, School of Medicine, University of California, Irvine, California 92697, USA
}

When the inaugural issue of RNA was released in 1995, I was learning about RNA in an undergraduate molecular biology course in China. At the time, RNA did not seem very glamorous to me; the textbooks said that it merely worked as the "middleman" between DNA and proteins. So when I came to the United States for graduate studies, RNA was not on my mind. During graduate school, however, a couple of events piqued my interest in RNA. The first was the publication of the Nature paper by Andrew Fire, Craig Mello and colleagues reporting the discovery of RNAi. In the following months, I could almost feel the electricity in the air as a worm lab in the department immediately started using RNAi in their experiments while another fly lab wasted no time in testing if the same methodology would work in Drosophila. Within a few months, they succeeded! Although my ecstatic friends were ultimately scooped, their excitement was so contagious that I caught the RNA bug myself. Then came the completion of the Human Genome Project in 2001. With the surprising realization that the human genome only contains about 20,000 genes, merely three times more than baker's yeast, it was predicted at the time that alternative splicing might be an important mechanism in higher eukaryotes for maximizing the proteomic diversity from limited genomic information. I was so convinced that I decided to bet my future career on mRNA processing.

Today as we celebrate the 20th anniversary of RNA, the mRNA processing field is very different than it was when I started 12 years ago. Much to my satisfaction, the early predictions about alternative splicing have panned out in a dramatic fashion. Now we know that alternative splicing is nearly ubiquitous in mammals and nearly $70 \%$ of eukaryotic genes produce alternatively polyadenylated mRNAs. Importantly, many of these events are regulated in a tissue- or developmental stage-specific manner and have critical functions. In addition, most, if not all, essential mRNA processing factors and an increasing number of regulatory factors have been identified and many have been characterized. The intricate connections between mRNA processing and other cellular events, including chromatin modification, other steps of gene expression, and signal transduction, have emerged. Our

\footnotetext{
Corresponding author: yongshes@uci.edu

Article and publication date are at http://www.rnajournal.org/cgi/doi/ 10.1261/rna.050674.115. Freely available online through the RNA Open Access option.
}

current knowledge about alternative splicing is at such a stage that it has allowed for the development of a "splicing code" that can predict tissue-specific or disease-associated splicing changes. How did this breathtaking progress come about? I am a strong believer that technology is the main driver of scientific discoveries. Looking back at past mRNA processing research, I think that the advancements in our field have been built upon three major technological systems. The first is the in vitro splicing and cleavage/polyadenylation assays developed in the eighties. These robust and sensitive assays allowed biochemists to isolate the core processing factors and regulatory factors, to characterize the assembly and disassembly of mRNA processing machineries, and to study the coupling between mRNA processing and other cellular events. The combination of in vitro processing assays and RNA tagging methods has led to the purification of the intact spliceosomes and the $3^{\prime}$ processing complexes and the subsequent structural analyses. More recently, the combination of in vitro processing assays and the latest single-molecule technology has provided novel insights into the dynamics of splicing. The second major research tool in our field has been genetics, mainly using Saccharomyces cerevisiae as a model system. For decades, the genetic and biochemical approaches have complemented each other perfectly, often converging on the same factors. Furthermore, given the high degree of complexity of the splicing and $3^{\prime}$ processing machineries and the difficulty in reconstituting and manipulating these machineries in vitro, genetic studies have provided exquisitely detailed insights into the inner workings and dynamics of these machines that were impossible to obtain otherwise. Third, the development of high throughput technologies heralded the transition from the "one-factor (or RNA processing event)-at-a-time" paradigm to the era of global analyses. Splicing-sensitive microarrays and RNAseq made it increasingly easier and cheaper to analyze alternative mRNA processing in any species. HITS-CLIP/CLIPseq and RIP-seq techniques allow us to map protein-RNA interactions at an unprecedented scale and resolution. The application of these technologies has provided quantitative and global insights into the functions of regulatory factors, often summarized in so-called "RNA regulatory maps." All of these

(C) 2015 Shi This article, published in RNA, is available under a Creative Commons License (Attribution-NonCommercial 4.0 International), as described at http://creativecommons.org/licenses/by-nc/4.0/. 
research tools have brought us where we are today and will continue to play a major role in future research.

What will the mRNA processing field be like in another 20 years? I believe that significant progress will be made on a number of important problems. Some of these problems require systematic and painstaking effort using the "tried-andtrue" methods, but others may depend on the development of new technologies. First, the function-structure relationship of the RNA processing machineries will be further elucidated. Although structural biologists have been working hard on this problem, our understanding of the structure and dynamics of the splicing and $3{ }^{\prime}$ processing machineries still lags far behind that of ribosomes or the transcription machinery. The progress in this area has been hampered at least in part by the complexity and the dynamic nature of these large machines. Therefore it will be important to develop methods to purify these complexes in large quantities and to enrich these dynamic particles at distinct steps. In addition, single molecule studies will also likely make a major contribution to our understanding of the dynamics of these RNA processing events. Second, we will need to transform data into real knowledge of the regulatory mechanisms for mRNA processing. Clearly we have become very good at generating data, from global mRNA processing profiling to protein-RNA interaction and RNA structure mapping. Many more assays are being developed to allow us to gather data on every aspect imaginable. To transform this wealth of data into real understanding, however, I believe that computational integration will be critical. In addition, any mechanistic model generated by high throughput analyses will need to be rigorously tested using low throughput methods such as the classic biochemical and/or genetic approaches. Third, we need a better understanding of the functions of alternatively processed mRNA isoforms. Although it is clear that most mammalian genes produce multiple alternatively processed mRNA isoforms, most functional studies have focused either on the "major" isoform or on all isoforms indiscriminately (e.g., in most knockout studies). So a major future challenge will be to identify and characterize the functionally important mRNA isoforms and to understand the biological consequence of their regulation in model organisms. The recent development of efficient genome editing techniques will greatly facilitate this effort. Finally, we need to translate our knowledge on mRNA processing into therapeutics. As aberrant mRNA alternative processing is involved in a large number of diseases, translational research in this area is urgently needed. Potential therapeutic tools, including antisense oligonucleotides and small molecules, have shown great promise and some are already in clinical trials. I am very optimistic that we will see the first mRNA processingtargeted drug in the next 20 years.

Looking back at the rich history and thinking ahead about the bright future of the RNA field, I feel extremely lucky to be a part of it! 

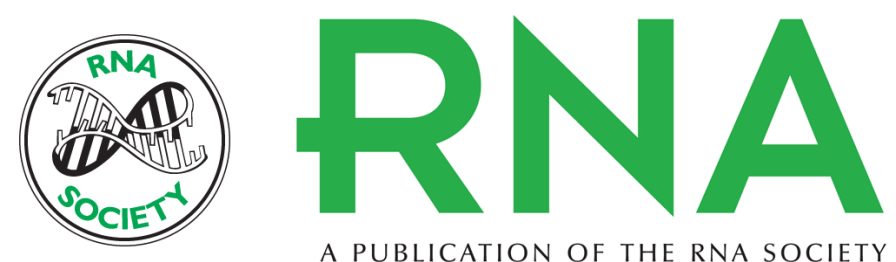

A PUBLICATION OF THE RNA SOCIETY

\section{Two decades of RNA as I see it}

Yongsheng Shi

RNA 2015 21: 733-734

Open Access Freely available online through the RNA Open Access option.

Creative This article, published in $R N A$, is available under a Creative Commons License Commons (Attribution-NonCommercial 4.0 International), as described at License http://creativecommons.org/licenses/by-nc/4.0/.

Email Alerting Receive free email alerts when new articles cite this article - sign up in the box at the Service top right corner of the article or click here.

To subscribe to $R N A$ go to:

http://rnajournal.cshlp.org/subscriptions

(C) 2015 Shi; Published by Cold Spring Harbor Laboratory Press for the RNA Society 